\title{
A EDUCAÇÃO EM ROUSSEAU: LIBERDADE COMO PONTO FULCRAL
}

\author{
LA EDUCACIÓN EN ROUSSEAU: LIBERTAD COMO PUNTO FULCRAL
}

\author{
Vital Ataíde da Silva \\ Universidade Estadual do Sudoeste da Bahia (UESB)
}

Joelson Alves Onofre

Instituto de Educação e Tecnologia Baiano

\section{Resumo}

A liberdade é ponto fulcral da educação em Rousseau. Esse tema descende de toda a sua obra. Se há um tema próprio de Rousseau é a liberdade, a qual identifica a natureza humana genuína, a ponto de ele afirmar que "negar a liberdade é negar a própria condição de homem". Esse trabalho ressalta a importância da educação em Rousseau como instrumento de formação de um novo homem como instrumento necessário à formação de uma nova sociedade, a qual se constitui pela formação de um cidadão autônomo e livre. Assim sendo, a educação preconizada por Rousseau tem como base a liberdade, nos termos daquilo que o autor acima sinaliza como característico do processo educacional desejável em vista da formação do homem e da constituição de uma sociedade fundada no "pactum unionis".

Palavras-Chave: Liberdade. Educação. Educação Natural.

\section{Resumen}

La libertad es punto central de la educación en Rousseau. Este tema desciende de toda su obra. Si hay un tema propio de Rousseau es la libertad, la cual identifica la naturaleza humana genuina, a punto de afirmar que "negar la libertad es negar la condición misma de hombre". Este trabajo resalta la importancia de la educación en Rousseau como instrumento de formación de un nuevo hombre como instrumento necesario a la formación de una nueva sociedad, la cual se constituye por la formación de un ciudadano autónomo y libre. Por lo tanto, la educación preconizada por Rousseau tiene como base la libertad, en términos de lo que el autor anterior señala como 
característico del proceso educativo deseable en vista de la formación del hombre y de la constitución de una sociedad fundada en el pactum unionis.

Palabras clave: Libertad. Educación. Educación Natural.

\section{Introdução}

A liberdade é ponto fulcral da educação em Rousseau. Esse tema descende de toda a sua obra. Se há um tema próprio de Rousseau é a liberdade, a qual identifica a natureza humana genuína, a ponto de ele afirmar que "negar a liberdade é negar a própria condição de homem". Esse trabalho ressalta a importância da educação em Rousseau como instrumento de formação de um novo homem como instrumento necessário à formação de uma nova sociedade, a qual se constitui pela formação de um cidadão autônomo e livre.

A formação que Rousseau preconiza deve levar à liberdade. A propósito, Soëtard (2010, p. 17) assevera: “[...] conquistar a própria liberdade e autonomia pessoal além do encontro conflituoso com a dura realidade do mundo, com a realidade do outro, com a da sociedade". E continua apresentando as prerrogativas do educador no âmbito daquilo que preconiza Rousseau:

É, então, que o educador recupera um papel decisivo, favorecendo a experiência formadora, acompanhando a criança ao longo de todo o seu itinerário, pleno de provas e de emboscadas, enfim e sobretudo, estimulandoo no momento em que se deve esforçar-se por reconstituir-se, por meio da ruptura de seu desejo. A arte do pedagogo consiste em atuar de maneira tal que sua vontade não substitua jamais a vontade da criança (SOËTARD, 2010, p. 17).

Assim sendo, a educação preconizada por Rousseau tem como base a liberdade, nos termos daquilo que o autor acima sinaliza como característico do processo educacional desejável em vista da formação do homem e da constituição de uma sociedade fundada no "pactum unionis".

Esse trabalho apresenta três tópicos, distribuídos da seguinte forma: 1) homem natural e homem civil; 2) educação natural como expressão da natureza humana e 3) educação de um novo homem para uma nova sociedade. Sendo o primeiro uma discussão cara a Rousseau que é a relação entre o homem natural e o homem civil. O segundo, por sua vez, considera a 
importância da educação natural como expressão da natureza humana, tema significativo para compreender o pensamento político de Rousseau. Por fim, o tema da educação como formadora de um homem novo em vista da constituição de uma nova sociedade, leva em consideração que uma sociedade livre e autônoma se origina da formação de um homem novo, um cidadão livre e autônomo.

\section{Homem natural e homem civil}

A proposta pedagógica de Rousseau, sustentada na liberdade, está diretamente relacionada com a relação entre o homem natural e o homem civil. Para compreender tal relação se faz necessário estabelecer a distinção entre aqueles dois estados. Essa distinção parte do conceito de natureza que Rousseau apresenta. Segundo ele, a natureza é o estado natural, ou seja, primitivo, de felicidade e harmonia, em que o homem se basta a si mesmo. Por isso a natureza é um dos temas de maior difusão na obra de Rousseau. Se o homem é naturalmente "bom", logo o estado de natureza é tranquilo, benigno. Interessante notar o que Dent (1999, p. 173) destaca a respeito da concepção de natureza. "Para Rousseau, a comunhão com a natureza afasta a pessoa da detestável sociedade de homens competitivos, e liberta-a para alegrar-se abertamente num mundo que expõe seus segredos a quem quer que lhe preste honesta atenção, despojado do egoísmo ou de propósitos mercenários" (DENT, 1999, p. 173).

Rousseau afirma que a natureza é inerente ao ser humano e, portanto, ao passo que se tem consciência das sensações, procura-se evitar as opiniões externas. O filósofo esclarece na seguinte citação:

Nascemos sensíveis e, desde o nosso nascimento, somos afetados de diversas maneiras pelos objetos que nos cercam. Assim que adquirimos, por assim dizer, a consciência de nossas sensações, estamos dispostos a procurar ou a evitar os objetos que as produzem, em primeiro lugar conforme elas sejam agradáveis ou desagradáveis, depois, conforme a conveniência ou inconveniência que encontramos entre nós e esses objetos, e, enfim conforme os juízos que fazemos sobre a idéia de felicidade ou de perfeição que a razão nos dá. Essas disposições estendem-se e firmam-se a medida que nos tornamos mais sensíveis e mais esclarecidos; forçadas, porém, por nossos hábitos, elas se alteram mais ou menos segundo nossas opiniões. Antes de tal alteração, elas são o que chamo em nós de natureza (ROUSSEAU, 1999, p. 10). 
A problemática que se coloca é o de conservar nessa natureza a sua qualidade originária. Para Jean-Jacques, não é possível conservar numa sociedade a mesma condição do estado natural já que o homem passará a viver com outros homens e isso se dá a partir do que ele chama de desnaturação. Esse processo acarretará no homem mudanças visíveis e significativas em seu estado natural.

As boas instituições sociais são as que melhor sabem desnaturar o homem, retirar-lhe sua existência absoluta para dar-lhe uma relativa, e transferir o eu para a unidade comum, de sorte que cada particular não se julgue mais como tal, e sim, uma parte da unidade, e só seja perceptível no todo (ROUSSEAU, 1999, p. 11).

Conforme Pissarra (2003, p. 41), “a meta da educação natural de Rousseau é aproximar o máximo possível, o homem desse estado natural, ainda que se saiba que ele não existe, nem nunca existiu”. E continua, "o que de concreto existe é o homem social, o homem é tão só o ideal a ser perseguido. O que define o homem social é a negação do homem natural”.

Rousseau define o homem social com aquele que sofreu uma transformação em sua essência mediante o contato com a sociedade corruptora. Segundo ele, "o homem civil é apenas uma unidade fracionária que se liga ao denominador, e cujo valor está em sua relação com todo, que é o corpo social" (ROUSSEAU, 1999, p. 11). Dessa forma, Pissarra (2003, p. 40) considera a degeneração do homem natural em homem social como inevitável e irreversível e que só pela via educacional é possível a total incompatibilidade entre o homem natural e o civil (social), só resta optar entre formar o homem ou o cidadão. Se Rousseau opta por formar o homem, certamente não pensa em fazê-lo viver nos bosques, mas sim formá-lo para viver na sociedade civil, onde o mesmo desempenhará seu papel enquanto cidadão.

Para Oliveira (1998, p. 14):

Rousseau descreve o homem da natureza que não é nenhum outro senão ele mesmo tal como ele próprio se imaginava. Esse homem dos primórdios da existência humana é na verdade uma espécie de modelo exemplar imaginário, representado numa época passada, enquanto possibilidade ideal e mítica. Rousseau, em seu tratado de educação propõe justamente o caminho de retorno à natureza. 
Oliveira (1998, p. 8) observa que "segundo Rousseau, com efeito, a natureza seria originária e essencialmente boa não corrompida pela civilização que é má. Ao homem caberá, portanto, auxiliar no devido progresso das potencialidades da humanidade enquanto espécie moral, buscando encontrar meios para não permitir que o potencial moral do ser humano desenvolva-se numa contraposição ao desenvolvimento das potencialidades do ser humano enquanto espécie natural”.

Rousseau chama atenção para uma diferença existente entre o que ele denomina homem que vive no estado de natureza e o homem que vive no estado de sociedade. Considera como fundamental essa passagem porque Emílio não foi educado como um animal selvagem, mas foi preparado para conviver com os outros homens. O método educacional proposto por Rousseau pretende projetar o homem como um ser sociável, que saberá viver bem e discernir as dificuldades que possivelmente ocorrerão durante a sua vida.

Ao mesmo tempo Rousseau idealiza uma sociedade bem ordenada, capaz de socializar os indivíduos em suas relações, assim:

Há muita diferença entre o homem natural que vive no estado de natureza e o homem natural que vive no estado de sociedade. Emílio não é um selvagem ao ser relegado aos desertos, é um selvagem feito para morar nas cidades. É preciso que saiba encontrar nelas o necessário, tirar partido dos habitantes e viver, senão com eles, pelo menos com eles (ROUSSEAU, 1999, p. 265).

Sabe-se que a idealização de uma sociedade organizada, pretendida por Rousseau, parece ser algo utópico, mas a garantia do sucesso de todo esse processo é conquistada pela via da educação. Destaca-se como ponto chave no pensamento rousseauniano a liberdade do homem a partir da educação que ele recebera. Em Rousseau, a liberdade ganha uma importância singular mais do que qualquer outro aspecto da vida humana. No Contrato Social, ele escreve: "Renunciar à sua liberdade é o mesmo que renunciar à sua qualidade de homem, aos direitos da humanidade, até mesmo a seus deveres" (ROUSSEAU, 1978, p. 80). Com isso, observa-se que Rousseau defende uma liberdade original ou "natural", ou seja, para ele as pessoas estão desde o nascimento isoladas, independentes dos adultos, sem nenhuma associação com outras pessoas. $O$ isolamento ao qual ele faz menção não deve ser interpretado de maneira equivocada. A hierarquia, a autoridade, a subordinação e o controle são totalmente contrários aos direitos originais dos seres humanos. Todos esses aspectos 
mencionados anteriormente atrapalham o desenvolvimento positivo da criança e consequentemente contribui para a formação de um ser humano altamente egoísta e dominador. "Cada pessoa é seu próprio e único juiz e senhor, não existe nenhum outro juiz ou senhor humano perante quem tenha que apresentar-se e prestar contas” (DENT, 1996, p. 157).

Os vários exemplos que Rousseau dá são oriundos de sua própria vivência e experiência pessoal, seja na infância ou na vida adulta. Ele direciona seu método educacional para o desenvolvimento do aluno a fim de que este se torne um ser social, dependente da liberdade. Sendo assim, a proposta pedagógica rousseaniana é de uma educação capaz de oferecer as condições de o homem viver em sociedade, contemplando a um só tempo o homem natural e o homem civil.

\section{Educação natural como expressão da natureza humana}

Quem lê Emílio ou da Educação, num primeiro momento acredita deparar-se com devaneios e sentimentos utópicos, embora o próprio Rousseau afirme preferir "ser homem de paradoxos a ser homem de preconceitos".

Rousseau afirma que a educação é fator preponderante na formação humana e que por isso deve ter início com o nascimento. A responsabilidade por esse itinerário educacional é atribuída à mãe, que deve cuidar e proteger o filho de todas as mazelas de uma sociedade corrompida. Rousseau compara o homem a uma planta que deve ser cultivada:

É a ti que me dirijo, terna e previdente mãe, que soube afastar-se da estrada principal e proteger o arbusto nascente do choque das opiniões humanas! Cultiva, rega a jovem planta antes que ela morra; um dia, seus frutos serão tuas delícias. Forma desde cedo um cercado ao redor da alma de teu filho; outra pessoa pode marcar o seu traçado, mas apenas tu podes colocar a cerca (ROUSSEAU, 1999, p. 7-8).

Rousseau, fiel à sua proposta de defender uma educação que obedeça à natureza, propõe quatro estágios com suas respectivas características que acompanham o desenvolvimento do homem, indo da idade da natureza (0 a 12 anos) passando pela idade da razão (12 a 15 anos) percorrendo Idade da força (15 a 20 anos) e finalmente atingindo idade da sabedoria (20 a 25 anos). Completando, ele aponta quais são nessas fases os elementos 
constitutivos do processo formativo, ou seja, para a educação do homem do nascimento até 2 anos de idade é recomendado uma vida em relação imediata com a natureza. Na segunda fase o único instrumento de aprendizagem para Emílio é a curiosidade. E mais, na terceira, o sentimento aí reinante para o homem educado é a amizade. Por fim, sugere que a responsabilidade e o compromisso social virão à tona com a maturidade na vida adulta (ROUSSEAU, 1999).

Ampliando a análise das fases de desenvolvimento Rousseau (1999) assegura que da fase de desenvolvimento chamada idade da razão nascem as ideias mais racionais que não estarão atreladas a questões práticas do dia a dia. A criança ampliará sua compreensão do que é imediato e conhecerá verdades e leis. E Dent (1996, p. 118) esclarece que: “A melhor maneira de fazer isso, [...] não é pela aprendizagem livresca nem a instrução passiva. O bom educador deve, antes, criar condições em que, a partir das exigências de uma situação prática, alguma lição mais ampla possa ser aprendida ou aplicada, para benefício imediato".

A educação, vê-se, deve ser a expressão de uma prática de igualdade e liberdade. Essa liberdade confere à criança a oportunidade de se deparar com algumas situações de sofrimento, sendo que não deverá sofrer intervenções dos adultos. É importante que a criança suporte o sofrimento e tire alguma lição dessa fase para que se torne um adulto apto a enfrentar as adversidades da vida, vejamos:

Se cair, se ficar com um galo na cabeça, se sangrar pelo nariz, se cortar os dedos, em vez de me agitar ao seu redor com um jeito alarmado, ficarei tranqüilo, pelo menos por um pouco de tempo. O mal está feito, é uma necessidade que ela o suporte; toda minha diligência só servirá para assustála ainda mais a aumentar a sua sensibilidade [...] Longe de estar atento a evitar que Emílio se machuque, eu ficaria muito aborrecido se ele nunca se ferisse e crescesse sem conhecer a dor. Sofrer é a primeira coisa que ele deverá aprender, e a que ele terá maior necessidade de saber [...] É nessa idade que se toma as primeiras lições de coragem e, suportando sem pavor as dores leves, aprende-se aos poucos a suportar as grandes (ROUSSEAU, 1999, p. 66).

Todo esse processo educacional de aprendizagem em que a criança deverá se submeter é sugerido por Rousseau para que ela mesma não se perca diante dos problemas que encontrará pela frente. Rousseau ainda tece uma crítica ao se referir à forma como se educa as crianças. Acredita-se, muitas vezes, que as mesmas não têm capacidade de aprender por si próprias. 
Nossa mania professoral e pedantesca é de sempre ensinar às crianças o que aprenderiam muito melhor por si mesmas, e esquecer o que só lhes poderíamos ensinar. Haverá algo mais tolo do que o trabalho que temos para ensiná-las a andar, como se tivéssemos visto alguém que, por descuido da ama-de-leite, não soubesse andar quando adulto? Pelo contrário, quantas pessoas vemos que andam mal por toda a vida porque lhes ensinaram mal a andar? (ROUSSEAU, 1999, p. 66).

Segundo Rousseau, o bem-estar beneficia a criança quando este compensa muitos machucados. "Em vez de deixá-lo estragar-se no ar corrompido de um quarto, que seja levado diariamente até um prado. Ali, corra, se divirta, caia cem vezes por dia, tanto melhor, aprenderá mais cedo a se levantar" (ROUSSEAU, 1999, p. 67). Essas observações são corroboradas por Soëtard (2010, p. 16) ao reiterar: "Rousseau critica de início toda a forma de educação fundada sobre o princípio de uma autoridade que submeta a vontade da criança à de seu mestre". E o próprio Rousseau voltar a essa questão ao questionar: "Que devemos pensar, então, dessa educação bárbara que sacrifica o presente por um futuro incerto, que prende uma criança a corrente de todo tipo e começa por torná-la miserável, para lhe proporcionar mais tarde não sei que pretensa felicidade que provavelmente não gozará jamais?” (ROUSSEAU, 1999, p. 68).

$\mathrm{Na}$ sociedade francesa em que a infância era desvalorizada, Rousseau enaltece a educação das crianças, assim como todas as fases de seu desenvolvimento. Considera a infância como a idade da alegria e chega a pedir aos homens que amem a infância. É a partir da infância que a criança deve ser bem-educada para que se torne um bom cidadão. $\mathrm{O}$ esmero com a educação que Rousseau demonstra no Emílio leva a perceber que é necessário preocupar-se com a formação do homem integral e isso só consegue por meio da educação. Para conseguir viver bem em sociedade, o homem precisa ser educado adequadamente desde o seu nascimento, para que, quando atingir a idade adulta possa inserir-se na sociedade e dela participar. E faz uma proclamação: "Homens, sede humanos, esse é o vosso primeiro dever, sede humanos para com todas as condições, para todas as idades, para tudo o que não é alheio ao homem. para vós, o que há fora da humanidade? Amai a infância, favorecei suas brincadeiras, seus prazeres, seu amável instinto" (ROUSSEAU, 1999, p. 68).

Essa defesa enfática da criança e de sua liberdade, contudo, não significa um posicionamento permissivo, pelo qual ela poderia livremente agir, pois segundo Dent (1996) 
observa Rousseau não teria ficado feliz, porém, com a tendência de certa educação centrada na criança que permite a esta pensar que pode fazer tudo o que seus impulsos lhe ditem, pois ele acredita que o capricho, admitido como lei seria inimigo de um crescimento bem sucedido. $\mathrm{O}$ que o genebrino defende é uma educação que acompanhando o processo natural de crescimento da criança favoreça o seu pleno desenvolvimento de suas potencialidades.

\section{Educação de um novo homem para uma nova sociedade}

Quando Rousseau recorre a um aluno imaginário, nesse caso Emílio, utiliza-o para refletir sobre como seria esse homem que é resultado de uma criança educada a partir da observação dos mecanismos da natureza humana. Pode-se comparar Emílio com todos os indivíduos que se mantém afastados da sociedade corrompida. Na atual sociedade, presenciase uma educação que prima pela construção de um papel meramente social. Longe desse procedimento, o que o filósofo propõe é educar Emílio para seguir o curso da natureza ara melhor viver em sociedade. Educar segundo a natureza significa deixar todos os preconceitos e ser guiado somente pela razão. Sendo assim, esse novo homem não deverá aceitar os valores estabelecidos na sociedade. Rousseau sugere a necessidade de resgatar o homem natural. E isso só será possível através de uma educação negativa e livre.

Se para Rousseau a sociedade corrompeu o homem, tornando-o vicioso, como afirmar que o homem não pode se tornar um ser social? Ora, para que o homem fique livre de todo tipo de corrupção na sociedade, essa mesma sociedade deve estar pautada em valores como moral e virtude. Em relação à forma como esse homem se relaciona com os outros, Nogaro e Pokojeski (2004) observam que ele nasce indefeso num mundo que ainda não compreende, dependendo dele para todas as suas necessidades para sua sobrevivência, pois não vivia com seu semelhante, preocupava-se somente com o momento presente, deixando de lado as ocupações "trabalhistas" ou da vida cotidiana permeada pelo mundo da produção.

No Emílio, a proposta de Rousseau recai na formação de um novo homem e de uma nova sociedade. A importância de educar para o relacionamento com o outro assume um valor inestimável. A nova sociedade à qual pensa Rousseau só será efetivamente construída mediante as relações sociais morais que se ensinam às crianças. O livro II do Emílio (ROUSSEAU, 1999) exemplifica a noção de propriedade através de um diálogo existente entre três personagens: Jean-Jacques, Emílio e Robert. O objetivo é mostrar à criança que ela

\begin{tabular}{l|l} 
Revista RBBA & Revista Binacional Brasil Argentina
\end{tabular} 
não é dona de tudo e por isso precisa saber distinguir entre o que é bom e o que é ruim. Reconhecer que é necessário estreitar relações e compreender os conceitos de meu e seu é uma advertência que Rousseau não abre mão. $\mathrm{O}$ aluno precisa discernir e construir juntamente com o mestre elementos que possam apontar para uma experiência promissora no que diz respeito ao amor de si e a generosidade para com o próximo. O entendimento sobre o que é propriedade, por parte do aluno, é de fundamental importância para Rousseau, visto que esse procedimento ajudará a criança a analisar até que ponto ela estava preparada para entender os ditames da sociedade. As convenções sociais mostram que as pessoas estão condicionadas a viverem conforme as regras e sansões que as impedem de exercer sua própria liberdade. $\mathrm{O}$ que o filósofo descreve são os dois sentimentos que existem em cada ser humano, o amorpróprio e a piedade natural. Na educação da criança deve-se atentar quanto ao surgimento desses sentimentos. Eles podem determinar também o comportamento moral da criança. Vejamos o que Rousseau diz a respeito no seguinte fragmento:

Robert: Oh, meus senhores, podeis ficar descansados, pois há muito poucas terras, baldias. Eu trabalho a que meu pai beneficiou. Cada qual por sua vez, faz a mesma coisa e todas as terras que vedes estão ocupadas há muito tempo. Emílio: Robert, então é freqüiente se perder a semente do melão? Robert: Desculpa, meu menino, pois não é sempre que encontramos senhorzinhos tão avoados como tu. Ninguém toca no jardim do vizinho; cada qual respeita o trabalho do outro, para que o seu fique em segurança. Emílio: Mas eu não tenho jardim. Robert: Que me importa? Se estragares o meu, não te deixarei mais passar por ele, pois não quero perder o meu trabalho. JeanJacques: Não poderíamos propor um acordo para o bom Robert? Que ele nos ceda, a meu amiguinho e a mim, um canto do seu jardim para cultiva-lo, com a condição de receber metade do produto. Robert: Eu o cedo sem condição, mas lembrai-vos de que irei lavrar vossas favas, se tocardes em meus melões. (ROUSSEAU, 1999, p. 100-101).

Nessa passagem encontra-se a ideia de que a propriedade remonta obviamente ao direito do primeiro ocupante pelo trabalho. Refletindo sobre o amor de si ao qual Rousseau se refere, observa-se que essa é a primeira paixão que o homem é movido a buscar. Essa paixão leva-o a lutar sempre pelo seu bem-estar. A criança, segundo Rousseau, desenvolve naturalmente esse sentimento, em contrapartida, não desenvolve em igual medida a segunda paixão que ele denomina de piedade natural. Piedade que se constitui num movimento essencial da alma, onde cada ser humano coloca-se no lugar do outro, saindo de si mesmo 
para experimentar a vida em grupo, em sociedade. Para Rousseau, a passagem do amor de si para a piedade natural tem uma conotação estritamente moral e política. O narcisismo, que é o mesmo que o amor-próprio é o que dá o tom na conduta da criança, isto é, se não for detectado precocemente. Quando nascemos, todos os sentimentos estão voltados para nós mesmos e para o nosso bem-estar.

A fonte de nossas paixões e o princípio de todas as outras, a única que nasce com o homem e nunca o abandona enquanto ele vive é o amor de si; paixão primitiva, inata, anterior a todas as outras e de que todas as outras não passam, em certo sentido, de modificações (ROUSSEAU, 1999, p. 273).

Para a nossa conservação, Rousseau sugere que nos amemos uns aos outros. Esse mesmo amor deve permear todo caminho educacional da criança. Afinal, cada criança vivencia esse primeiro sentimento devendo também amar o próximo. Rousseau preocupa-se com a forma como a criança deve ser educada para que futuramente venha se tornar um adulto consciente e feliz. O primeiro sentimento de uma criança é amar a si mesma, e o segundo, que deriva do primeiro é amar os que lhes são próximos, pois no estado de fraqueza em que se encontra não conhece ninguém a não ser pela assistência e pela atenção que recebe (ROUSSEAU, 1999, p. 274)

Ora, se a criança já possui o amor se de si logo quando nasce, para Rousseau, cabe à educação o papel primordial de ativar a piedade natural nessa criança Rousseau não idealizou um aluno para ser educado numa floresta, isolado do mundo, mas para viver numa sociedade pervertida, onde ele mesmo terá que utilizar das ferramentas que dispõe para aplicar sua noção de propriedade e de censo crítico.

Dent (1999, p. 37) afirma que “o amor de si mesmo não está exclusivamente confinado a padrões instintivos de comportamento. Essa mesma preocupação geral pelo bemestar individual manifesta-se quando entram em jogo a percepção consciente, a previsão e o conhecimento dos componentes do bem individual". Dentro dessa mesma perspectiva, dá-se uma passagem do amor de si para o amor próprio, carregado de impulsos contundentes, chamados por Rousseau (1999, p. 309) de paixões:

Tendo Emílio até o presente olhado apenas para si mesmo, o primeiro olhar lança a seus semelhantes leva-o a comparar-se a eles, e o primeiro sentimento que excita nele esta comparação é desejar o primeiro lugar. Eis o 
ponto em que o amor de si se transforma em amor-próprio e onde começam a nascer todas as paixões que dele dependem.

Diferentemente do amor de si mesmo, Rousseau desenvolve seu pensamento a respeito do amor próprio que nada mais é do que o sentimento de vaidade presente no ser humano. Segundo ele, "o amor-próprio é um instrumento útil, mas perigoso; não raro fere a mão que dele se serve e raramente faz o bem sem o mal" (ROUSSEAU, 1999, p. 323). Compartilhando da mesma opinião sobre o caráter perigoso do amor-próprio e como este se traduz em manifestações de egoísmo, Dent (1996, p. 40) pontua:

\begin{abstract}
[...] Rousseau sustenta que, logo que um ser humano toma qualquer espécie de relação ou associação estável com outro, isso suscita nele um desejo, que rapidamente de se torna dominante e absorvente, de estabelecer-se como superior ao outro, de adquirir um poder arbitrário e despótico, de impor submissão e ignomínia ao outro, em cuja degradação encontra-se prazer e prova de sua própria importância e valor. As relações humanas são assim completamente desfiguradas por um desejo insaciável de dominação e prestígio, que exige e impõe deferência e subordinação.
\end{abstract}

Rousseau pretende alertar os pais e educadores para os sinais visíveis do amor-próprio que são inerentes em cada ser humano, ou seja, se a educação não primar pela preservação do caráter de cada criança, certamente prevalecerão o sentimento de competição e egoísmo. Quando Rousseau afirma que o homem é bom por natureza é porque acredita que seu método é a natureza. Bem, o homem é bom, mas ao mesmo tempo vive numa sociedade onde estabelece relações com outras pessoas. O homem em contato com a sociedade evidencia o amor-próprio, isto é, o primeiro sentimento de competitividade é percebido a partir do momento em que se encontra em conflito consigo mesmo e com os outros.

Parafraseando Rousseau, Dent (1999, p. 40) acrescenta: “uma vez que o contato social destaca o amor-próprio, e uma vez que o amor próprio é inexoravelmente nocivo e corruptor, Rousseau considera muito escassa, de fato, as perspectivas para os humanos viverem vidas fecundas e gratificantes juntos em sociedade”. Apesar de Rousseau destacar esses sentimentos que estão presentes na criança, observados a partir da educação, ele ainda adverte ao jovem que é necessário conhecer a bondade humana. 
Saiba ele que o homem é naturalmente bom, sinta-o, julgue seu próximo por si mesmo; mas veja ele como a sociedade deprava e perverte os homens; seja levado a estimar cada indivíduo, mas despreze a multidão; veja que todos os homens carregam mais ou menos a mesma máscara, mas saiba também que existem rostos mais belos que as máscaras que os cobre (ROUSSEAU, 1999, p. 311).

Para perceber a bondade humana não basta apenas isolar o homem de seus compromissos ou educá-lo longe das outras pessoas. Urge fazer com que sinta seu coração, porém não esquecendo de que a razão é que deve conduzi-lo. Posto dessa maneira, Rousseau defende a educação do homem livre, que possa transpor todas as barreiras dogmáticas das opiniões alheias, colocando em confronto direto com a realidade que o circunda. Sendo assim, tem-se um homem que se percebe e percebe o outro. A forma como Rousseau concebe a maneira de formar o homem livre, destaca-se o seguinte fragmento:

Mas considerai primeiro que, querendo formar o homem da natureza, não se trata por isso de fazer dele um selvagem e de relegá-lo ao fundo dos bosques, mas envolvido num turbilhão social, basta que ele não deixe arrastar nem pelas paixões nem pelas opiniões dos homens; veja ele pelos seus olhos, sinta pelo seu coração; não o governe nenhuma autoridade, exceto a de sua própria razão. (ROUSSEAU, 1999, p. 339).

Outro ponto que é interessante notar é quando Rousseau no livro II do Emílio fala da piedade ou compaixão como fundamental para alicerçar a possibilidade de relações criativas, cooperativas e benévolas entre as pessoas, tanto no âmbito individual como social. As preocupações combativas, competitivas e agressivas oriundas do amor-próprio não fazem parte da esfera da compaixão. Nela encontramos a base para uma forma de relações humanas alternativa. Através dessa piedade (compaixão), as pessoas podem chegar a sentir um interesse a ajudar as outras pessoas. O que Rousseau escreve em seu ensaio pedagógico objetiva esboçar os procedimentos elementares que deveriam ser obedecidos criteriosamente a fim de tornar a criança de hoje em um bom adulto de amanhã.

Sartre (1987, p. 9) concorda com Rousseau quando diz que o homem é livre, mas é responsável por tudo o que faz. “[...] É o que posso expressar dizendo que o homem está condenado a ser livre. Condenado, porque não se criou a si mesmo, e como, no entanto, é livre, uma vez que foi lançado no mundo e é responsável por tudo o que faz".

Pensando dessa forma, infere-se que na educação o processo se dá quase da mesma forma. Minha educação também depende da educação da educação do outro, assim como a \begin{tabular}{l|l} 
Revista RBBA & Revista Binacional Brasil Argentina
\end{tabular} 
liberdade citada por Sartre que também depende da liberdade do outro. "E, querendo, a liberdade, descobrimos que ela depende integralmente da liberdade dos outros, e que a liberdade dos outros depende da nossa [...] não posso ter como objetivo a minha liberdade a não ser que meu objetivo seja também a liberdade dos outros" (SARTRE, 1987, p.19).

É fundamental observar no percurso educacional a presença desses três sentimentos: amor de si mesmo, amor-próprio e a piedade natural. Rousseau salienta que eles acompanham o homem desde o seu nascimento até a fase adulta. Eles serão determinantes para que o homem atinja o estágio onde se perceba como um ser social, um cidadão.

\section{Considerações Finais}

A pedagogia de Rousseau tem como ponto fulcral a liberdade, a qual se constitui em instrumento de desenvolvimento da criança em seu percurso de amadurecimento até atingir a idade adulta. Ora, a liberdade que Rousseau preconiza é aquela capaz de oferecer à criança o pleno uso de sua capacidade, originada da sua própria natureza. Esse é propriamente o sentido dado por Rousseau ao conceito de Educação Negativa.

O que buscamos apresentar nesse trabalho foi como Rousseau insere sua discussão sobre a educação no tema da relação entre o homem natural e o homem civil, considerando ser a educação natural o caminho para garantir uma educação que respeita o homem em condições naturais; de modo que estas sejam preservadas em todo itinerário formativo desde a primeira infância até a maturidade. Esses temas, nesse trabalho, se concluem pela afirmação de uma educação que se dirige à formação de um novo homem em vista da formação de uma nova sociedade.

\section{Referências}

CERIZARA, Ana Beatriz. Rousseau: A educação na Infância. São Paulo: Scipione, 2001.

DENT, N. J. H. Dicionário de Rousseau. Trad. Álvaro Cabral. Rio de Janeiro: Jorge Zahar Editor, 1996.

GHIRALDELLI, Paulo Jr. (Org). O que é Filosofia da Educação? 3. ed. Rio de Janeiro: DP\&A, 2002. 
JESUS, Charlas Oliveira de. Rousseau: uma libertadora educação para a felicidade. 2005. 39p. Monografia (apresentada ao final do Curso de Graduação em Filosofia) Universidade Estadual de Santa Cruz, Ilhéus-BA.

JOSÉ, Francisco; FALCON, Calazans. Iluminismo. 3. ed. São Paulo: Ática, 1991 (Série Princípios).

NOGARO, Arnaldo; POKOJESKI, Sueli. O conceito de educação no Emílio de Rousseau. In: Revista Espaço Pedagógico. Faculdade de Educação. Universidade de Passo Fundo. Vol.11, $\mathrm{n}^{\circ}$ 2, jul/dez - 2004. Rio Grande do Sul, UPF. 92 - 110p.

OLIVEIRA, Adailson Henrique Miranda. Da liberdade da igualdade à idéia de superação da desigualdade social em Jean-Jacques Rousseau. 1998. 28p. Monografia (apresentada ao final do Curso de Pós-Graduação Lato-sensu em Filosofia Contemporânea) Universidade Estadual de Santa Cruz, Ilhéus-BA.

PISSARRA, Maria Constança. Rousseau: a política como exercício pedagógico. São Paulo: Moderna, 2003 (Coleção Logos).

ROUSSEAU, Jean-Jacques. O Contrato Social. Trad. Vicente Sabino Junior. São Paulo: José Bushatsky Editor, 1978.

Fontes, 1999.

Emílio ou da Educação. Trad. Roberto Leal Ferreira. 2. ed. São Paulo: Martins

SARTRE, Jean Paul. O Existencialismo é um Humanismo. Trad. Rita Correia Guedes. 3. ed. São Paulo: Nova Cultural, 1987 (Coleção Os Pensadores).

SOËTARD, Michel. Jean-Jacques Rousseau. Tradução: Verone Lane Rodrigues Doliveira. Recife: Fundação Joaquim Nabuco, Editora Massagana, 2010. (Coleção Educadores).

\section{Sobre os autores}

Vital Ataíde da Silva. Doutorando em filosofia pela UFBA, Mestre em filosofia pela UFBA, Especialização em Filosofia Contemporânea pela UESC e Graduado (Licenciatura e Bacharelado) em Filosofia pela UFPB. Professor Assistente de filosofia e Metodologia Científica da Universidade Estadual do Sudoeste da Bahia - UESB, Campus de Jequié/BA. Endereço Eletrônico: vitalesperanca@hotmail.com

Joelson Alves Onofre. Professor EBTT de Filosofia no Instituto de Educação e Tecnologia Baiano - IFBaiano Campus Senhor do Bonfim. Mestre em Educação pela UFBA, Especialista em Educação e Relações Étnico-raciais, pela UESC, Licenciado em Filosofia pela UESC e em Pedagogia pelo Centro Universitário Claretiano. Endereço Eletrônico: Janofrecp@yahoo.com.br 